\section{Alteration of biomarkers of expired and cured COVID- 19 ICU patients in a tertiary care hospital}

\author{
Abu Hasan', Rummana Rahim² ${ }^{\star}$ Mizanur Rahman ${ }^{3}$ \\ ${ }^{1}$ Senior Scientific Officer, Molecular Diagnostics Lab, Evercare Hospital Dhaka, Plot- 81, Block- E, \\ Bashundhara R/A, Dhaka-1229, Bangladesh. \\ ${ }^{2}$ Specialist, Molecular Diagnostics Lab, Evercare Hospital Dhaka, Plot- 81, Block- E, Bashundhara R/A, \\ Dhaka-1229, Bangladesh. \\ ${ }^{3}$ Senior Consultant, Molecular Diagnostics Lab, Evercare Hospital Dhaka, Plot- 81, Block- E, \\ Bashundhara R/A, Dhaka-1229, Bangladesh.
}

Bioresearch Communications

Volume 7, Issue 2, July 2021

DOI:

https://doi.org/10.3329/brc.v7i2.54378

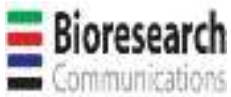

\begin{abstract}
Coronavirus Disease 2019 (COVID-19) is a respiratory disease caused by severe acute respiratory syndrome coronavirus 2 (SARS-CoV2). This is a retrospective observational study aimed to find the alteration of some biochemical and hematological parameters of 121 COVID-19 patients admitted in intensive care unit (ICU) of Evercare Hospital Dhaka during May to December 2020. Methods: Retrospective biochemical, hematological and molecular (COVID-19 RT-PCR Ct value) markers were analyzed on COVID-19 patients in ICU and compared on those who died in the ICU and those cured. Results: Comparison of viral titer assessed by RT-PCR Ct values of target genes of SARS-CoV-2 among cured and expired patients did not show any significant differences. However, biochemical parameters such as CRP, Ferritin and hematological parameters such as WBC, absolute neutrophil, absolute lymphocyte, D-dimer showed significant differences among cured and expired patients. Patients who died in ICU mean CRP, Ferritin, D-dimer, WBC, absolute neutrophil were 10.39, 7694.30, 3196, 16.38, 15.12 respectively, compared to cured patients 0.93 , $457.57,773,11.24,8.86$ respectively, with $95 \%$ confidence interval $(95 \% \mathrm{Cl})$. Platelets and absolute lymphocytes were observed decreased in expired patients compared to cured. Further, elevated level of neutrophil to lymphocyte ratio (NLR) and reduced level of lymphocyte to C-reactive protein ratio (LCR) has significant correlation with disease severity. Conclusion: These findings indicate that biochemical parameters such as CRP, Ferritin and hematological parameters such as CBC, D-Dimer, NLR, LCR can be monitored to identify severity and fatality of COVID-19 patients and thus, may help in improving disease outcome.
\end{abstract}

KEYWORDS: COVID-19, SARS-CoV-2, ICU, D-Dimer, CRP, Ferritin, NLR.

RECEIVED: 19 March 2021, ACCEPTED: 11 June 2021

TYPE: Original Research
CORRESPONDING AUTHOR: Dr. Rummana Rahim, Specialist - Molecular Diagnostics Lab, Evercare Hospital Dhaka

Email: rummanarahim@yahoo.com

\section{Introduction}

The present outbreak of Coronavirus Disease 2019 (COVID19) has become a common international concern and reached to more than 220 countries around the globe [1]. According to the World Health Organization (WHO), the current COVID19 pandemic caused by a coronavirus named Severe Acute Respiratory Syndrome Coronavirus 2 (SARS-CoV-2) belonging to the Coronaviridae family which was first detected in December 2019 in the city of Wuhan, Hubei province in China. Over the last 17 months of its spread, till $30^{\text {th }}$ April 2021, approximately $152,113,053$ positive cases and $3,196,373$ deaths were reported worldwide owing to the high transmission efficiency of SARS-CoV-2 [2]. Coronaviruses (CoVs) are single stranded RNA viruses classified into four genera: alpha-, beta-, gamma- and delta-CoV ; SARS-CoV-2 is a $\beta-\operatorname{COV}[3]$.

COVID-19 primarily manifested as a respiratory tract infection with symptoms of fever, dry cough and fatigue; in severer cases, dyspnea and may also manifest as systemic infection. It also involves multiple organs including cardiovascular, gastrointestinal tract, liver, kidney, neurological, hematopoietic and immune system $[4,5,6,7,8,9]$. SARS-CoV-2 being a systemic disease, inflammatory reactions can prompt changes in the biochemical composition of the peripheral blood [10]. Numerous laboratory parameters make it possible to assess the severity of the disease and make it conceivable to evaluate its risk of developing towards more serious afflictions like acute respiratory distress syndrome (ARDS), disseminated intravascular coagulation (DIC) and multiple organ failure (MOF) [11].Comorbidities associated with more severe outcomes from COVID-19 with diabetes, obesity, hypertension, heart disease, chronic kidney disease, and chronic pulmonary disease. Specifically, in kids and young adults, numerous infections were found to be asymptomatic. In contrast, older people and individuals with comorbidities are at a greater danger of severe illness, respiratory failure and death [12].

The laboratory medicine plays a vital role to support for appropriate clinical management of COVID-19 patients, from screening to diagnosis, prognosis and monitoring. Biochemical and hematological parameters retain a clinical and biological significance, which can improve diagnostic reasoning and management of patient care with suspected severity of infection [13]. In our study, statistically significant differences in terms of age, length of stay, assessment of viral titer by RT-PCR Ct values, White Blood Cell (WBC), Red Blood Cell (RBC), C-Reactive Protein (CRP), ferritin, D- 
Dimer, K, Na, Neutrophils, Lymphocytes, Monocytes, Eosinophil, Platelets, Hemoglobin were evaluated. In a study in New York city, it was shown that viral load is lower in hospitalized patients than non- hospitalized and viral load has no correlation with disease severity \& outcome in hospitalized patients. [14]. Though some biochemical parameters and hematologic parameters has been reported elevated and/or decreased in COVID-19 hospitalized and non-hospitalized patients in different cohorts there is scarcity of report about comparative analysis between cured patients from ICU and expired patients in ICU [15 - 17]. Analyzing alteration of various parameters of COVID-19 patients in ICU in our cohort may effectively identify critically ill patients much earlier and thus may help to reduce mortality and improve recovery.

\section{Materials and Methods}

\section{Patient Population and Data Collection:}

The data of the patients were taken from hospital information system of Evercare Hospital Dhaka, situated at Bashundhara Residential Area, Dhaka, Bangladesh and the study period was May to December 2020. We included total 121 ICU admitted COVID-19 patients and divided them into two groups: cured (36) and expired (85). Adult population were included in this study (>18 years old). Age range of study population was in between 22 years to 93 years with predominance of $>55$ years of age. After confirmation of COVID 19 positive cases by RTPCR, we analyzed the mean $\mathrm{Ct}$ value of target region, patient's age, length of stay, White Blood Cell (WBC), Red Blood Cell (RBC), Hemoglobin C-Reactive Protein (CRP), ferritin, D-Dimer, K, Na, Neutrophils, Lymphocytes, Monocytes, Eosinophil, Platelets level in both groups.

As it is a data based retrospective study, patient consent is not required in these cases.

\section{Molecular Testing for COVID 19 SARS-CoV-2 detection:}

Nasopharyngeal swabs were collected from all patients presenting suspected COVID19 infection to Evercare Hospital Dhaka by trained medical personnel. The collected swabs were immediately transferred to viral transport medium (VTM) and sent to Molecular Diagnostics Lab for further testing.

For RT-PCR, sample containing VTM was extracted by KingFisher Flex-automated extraction analyzer (Thermo Fisher Scientific, USA) and magnetic based extraction MagMAX Viral/Pathogen Kit (Applied Biosystems by Thermo Fisher Scientific, USA) was used. PCR was done by Novel Coronavirus (2019-nCoV) Nucleic Acid Diagnostic Kit (Sansure Biotech, China) and procedure was followed according to the manufacturer's instructions. For each sample, master mix $15 \mu 1$ and extracted RNA $10 \mu 1$ was used.

This assay utilizes double target genes, '2019-nCoV ORF$1 \mathrm{ab}$ ' and specific conserved sequence of coding nucleocapsid protein ' $\mathrm{N}$ gene' as the target regions. The PCR detection system uses the positive internal control (RNase P), which monitor the presence of PCR inhibitors in test specimen by detecting whether the internal control signal is normal, to avoid a false negative result. The result was considered valid when the cycle threshold $(\mathrm{Ct})$ value of the reference gene was $<40$. The result was considered positive when the $\mathrm{Ct}$ value of all three targets were $<40$ with typical $\mathrm{S}$ - shaped curve and negative when there were no $\mathrm{Ct}$ or $\geq 40$.

\section{Hematological parameters detection:}

Complete Blood count (CBC) including WBC, $\mathrm{RBC}, \mathrm{Hb}$, Platelet, Neutrophil, Lymphocyte, Monocyte, Eosinophil, was detected by Sysmex XN 2000 Automated Hematology analyzer (Sysmex corporation, Japan). The fibrin degradation product D-dimer is commonly used to test and evaluate clot formation, and it is measured through Sysmex CS-1600 automated hemostasis benchtop analyzer (Sysmex corporation, Japan).

\section{Biochemical parameters detection:}

Inflammation was detected using the C-reactive protein (CRP) test through BN ProSpec System (Siemens, Germany) and DxC 700AU clinical chemistry analyzer (Beckman Coulter, USA).

Ferritin test was used to determine how much iron the human body can store, and it is done by Dimension EXL 200 System (Siemens, Germany) and ADVIA Centaur XP (Siemens, Germany).

Electrolyte imbalance is a common presentation of COVID-19 patient and measured by Dimension EXL 200 System (Siemens, Germany) and DxC 700AU clinical chemistry analyzer (Beckman Coulter, USA).

\section{Data Processing and Analysis:}

The researcher collected all data. After collection, data was cross-checked by co-researchers in case of inconsistency. The collected data were processed and analyzed using SPSS (Statistical Package for Social Science) software version 26.0. Primarily descriptive statistics was done as appropriate. Multiple logistic regression was done to identify the factors associated with increased risk of unfavorable outcome after adjusting for potential confounders and checking for multicollinearity (with p-value $<0.05$ as significant).

A p-value of $<0.05$ was considered statistically significant. All the highly significant values were rounded off as $<0.001$.

\section{Results}

\section{Population demography}

The mean age of the study population of expired patients was 65.68 ranging from 22 to 93, including 54 male and 31 females. On the other hand, mean age of cured patient was 56.83 ranging from 30 to 80 , including 22 males and 14 females. The most common age group was 50 -80 years, with two-thirds of them being males (Table 1). 
Table 1. Age and sex distribution of study population

\begin{tabular}{cll}
\hline Study Population & Expired & Cured \\
\hline Total Population (n=121) & 85 & 36 \\
\hline Age range (Years) & $22-93$ & $30-80$ \\
\hline Mean age (Years) & 65.68 & 56.83 \\
\hline Male (n) & & 22 \\
\hline Mean age of Male (Years) & 54 & 60 \\
\hline Female (n) & 65.63 & 14 \\
\hline Mean age of Female (Years) & 31 & 54.85 \\
\hline
\end{tabular}

\section{Hospital stays}

The average length of stay at hospital Intensive Care Unit (ICU) varies between two groups. In our study, we found range of hospital stay of expired patient was about $3-43$ days and in cured group it was $3-19$ days. The mean value of average stay of expired and cured was $14.13 \& 8.73$ days respectively, and the difference is statistically significant $(\mathrm{P}$ value is $<0.001)$.

\section{COVID-19 RT-PCR Ct value}

Detection of SARS-CoV-2 by the reverse transcription-PCR (RT-PCR) assay in nasopharyngeal swab specimens was the diagnostic method for COVID-19. We used qualitative RTPCR for the detection of virus. Though it is qualitative method, viral titer can be roughly assessed by $\mathrm{Ct}$ value. The amount of viral RNA copies present in the positive samples is inversely proportional to the corresponding $\mathrm{Ct}$ value. That means, the greater the amount of viral RNA, the lower the $\mathrm{Ct}$ value. A $\mathrm{Ct}$ value of $<25$ (both targets ORF-1ab \& $\mathrm{N}$ gene) indicates high viral load, $\mathrm{Ct}>30$ indicates low viral load and in between 25-30 indicates moderate [18]. The mean $\mathrm{Ct}$ value of both targets (ORF-1ab \& N gene) of expired patients found $24.16 \& 22.46$ and in cured it was $23.92 \& 22.46, \mathrm{P}$-value of
ORF-1ab \& N gene is $0.43 \& 0.49$ respectively, indicates no significant differences.

\section{Hematological and Biochemical parameters}

In our ICU out of 121 COVID-19 patients, 85 was expired and 36 cured. Among 85 expired patients, CRP, ferritin, D-dimer, WBC, absolute neutrophil, neutrophil to lymphocyte ratio (NLR) was increased from normal value in $93.67 \%, 84.81 \%$, $97.56 \%, 66.67 \%, 83.33 \%, 95.12 \%$ cases respectively and lymphocyte, platelet count was decreased in $56.79 \%$ \& $67.06 \%$ cases, respectively.

Mean value of biomarkers CRP, ferritin, D-dimer, WBC, absolute neutrophil, neutrophil to lymphocyte ratio (NLR) is much higher among the expired patients compared to cured patients. On the other hand, red blood cell (RBC), absolute lymphocyte, absolute eosinophil, lymphocyte to C-reactive protein ratio (LCR), hemoglobin $(\mathrm{Hb})$ \& platelet count is found lower among the expired patients (Table-2).

Then we analyzed how much alteration of mean value of each parameter happened in both expired and cured groups (Figure 1). It shows that the cured and expired patients have a visual and statistical alteration of hematological \& biochemical parameters.

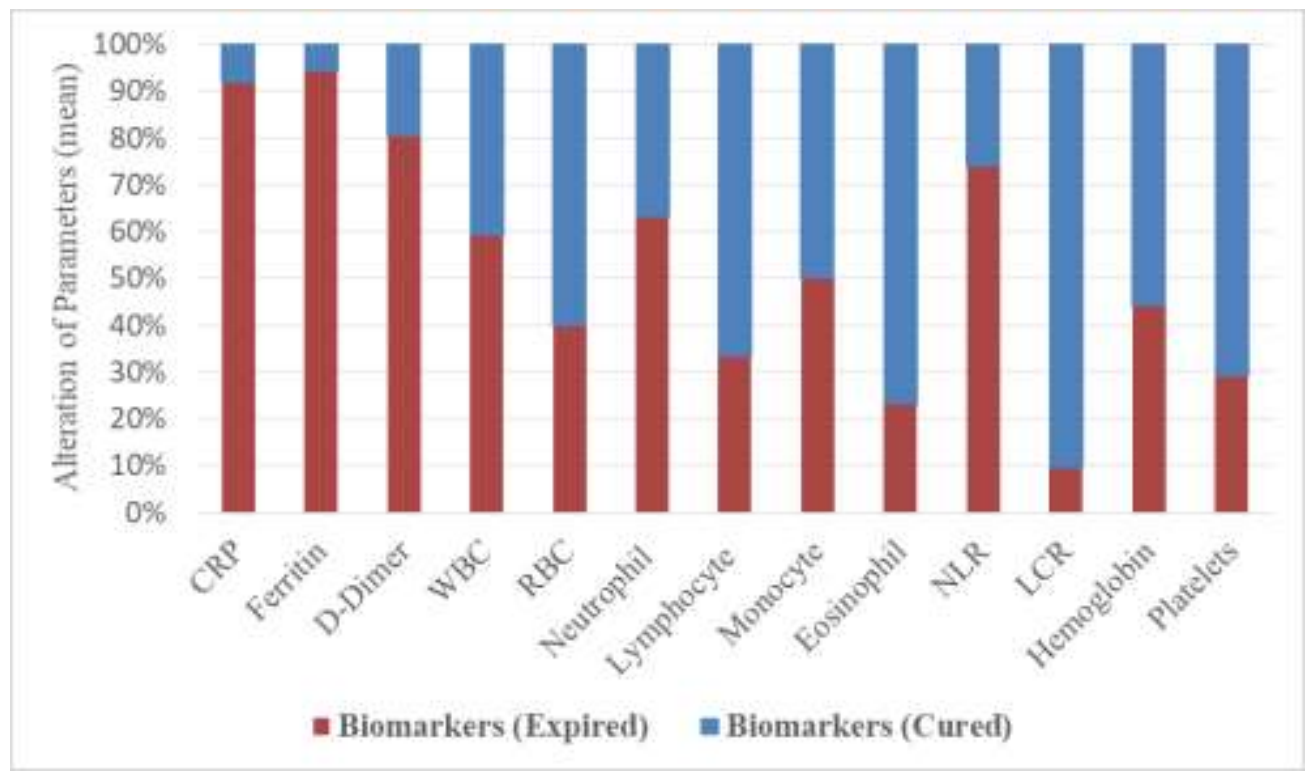

Figure 1. Hematological \& biochemical alteration in COVID-19 ICU cured and expired patients 


\section{Neutrophil to lymphocyte ratio (NLR)}

We calculated NLR by dividing the absolute neutrophils count $\left(\mathrm{x} 10^{9}\right.$ cells/L) by absolute lymphocytes $\left(\times 10^{3}\right.$ cells $\left./ \mathrm{uL}\right)$. Normally, it should be below 3 , but a ratio of above 3 signifies acute stress, and a ratio of more than 9 signifies sepsis. But variability occurs in populations regarding the cut-off value of NLR, with some studies suggesting a cut-off value of 4 [19]. In our study, mean NLR in expired patients is 18.62 and in cured patients it is 6.56. The difference is statistically significant as because $\mathrm{p}$-value is $<0.001$.

\section{Lymphocyte to monocyte ratio (LMR)}

It was calculated by dividing absolute lymphocyte count $\left(x 10^{3}\right.$ cells/uL) with absolute monocyte count $\left(\times 10^{3}\right.$ cells/uL) [20]. The normal range is 3-9 with variability amongst populations [4]. In our study, mean LMR in expired and cured patients is $5.27 \& 6.62$ and $P$ value found 0.22 . As the $\mathrm{p}$-value is above 0.05 , it is not statistically significant.

\section{Platelet to lymphocyte ratio (PLR)}

It was calculated by dividing absolute platelet counts $\left(\times 10^{3}\right.$ cells/uL) with absolute lymphocyte count $\left(\times 10^{3}\right.$ cells/uL), which usually lies in between 50 and 150 but subjected to variability amongst populations [4]. In our study, PLR in expired and cured patients is $224.01 \& 192.57$ and $\mathrm{P}$ value found 0.24 . It is not statistically significant.

\section{Lymphocyte to C-reactive protein ratio (LCR)}

This marker was calculated by dividing the absolute lymphocyte count $\left(\mathrm{x} 10^{3}\right.$ cells/uL) with CRP levels $(\mathrm{mg} / \mathrm{dl})$ [21]. In our study, LCR in expired patients is 0.14 and in cured it is about 1.31 and $\mathrm{P}$ value is 0.002 which is statistically significant. It is an indicator of inflammatory mediator and low value indicates higher mortality with a declined prognosis [22].

Above ratio analysis indicates that COVID-19 patients in ICU, NLR \& LCR can determine the severity and outcome of disease.

Table 2. Biomarkers of expired and cured patients

\begin{tabular}{|c|c|c|c|c|c|}
\hline \multirow[t]{2}{*}{ Parameters } & \multirow[t]{2}{*}{ Unit } & \multicolumn{2}{|c|}{ Mean Values of patients } & \multirow[t]{2}{*}{ P-value } & \multirow{2}{*}{$\begin{array}{c}\text { Statistically } \\
\text { Significant (Yes } \\
\text { No) }\end{array}$} \\
\hline & & Expired & Cured & & \\
\hline $\begin{array}{c}\text { C-Reactive } \\
\text { Protein (CRP) }\end{array}$ & $\mathrm{mg} / \mathrm{dl}$ & 10.39 & 0.93 & $<0.001$ & Yes \\
\hline Ferritin & $\mathrm{ng} / \mathrm{mL}$ & 7694.30 & 457.57 & $<0.001$ & Yes \\
\hline D-Dimer & $\mu \mathrm{g} / \mathrm{L}$ & 3196 & 773 & 0.004 & Yes \\
\hline $\begin{array}{l}\text { White Blood Cell } \\
\text { (WBC) }\end{array}$ & $\mathrm{x} 10^{\wedge} 9 / \mathrm{L}$ & 16.38 & 11.24 & 0.001 & Yes \\
\hline $\begin{array}{l}\text { Red Blood Cells } \\
\text { (RBC) }\end{array}$ & $\mathrm{x} 10^{\wedge} 12 / \mathrm{L}$ & 3.9 & 4.6 & 0.237 & No \\
\hline Hemoglobin (Hb) & $\mathrm{gm} / \mathrm{dl}$ & 12.36 & 12.85 & 0.369 & No \\
\hline $\begin{array}{l}\text { Absolute } \\
\text { Neutrophil }\end{array}$ & $\mathrm{x} 10^{\wedge} 3 / \mu \mathrm{L}$ & 15.12 & 8.86 & $<0.001$ & Yes \\
\hline $\begin{array}{c}\text { Absolute } \\
\text { Lymphocyte }\end{array}$ & $x 10^{\wedge} 3 / \mu \mathrm{L}$ & 0.99 & 1.98 & $<0.001$ & Yes \\
\hline $\begin{array}{l}\text { Absolute } \\
\text { Monocyte }\end{array}$ & $x 10^{\wedge} 3 / \mu \mathrm{L}$ & 0.43 & 0.43 & 0.49 & No \\
\hline $\begin{array}{l}\text { Absolute } \\
\text { Eosinophil }\end{array}$ & $\mathrm{x} 10^{\wedge} 3 / \mu \mathrm{L}$ & 0.11 & 0.18 & 0.087 & No \\
\hline Platelets & $\mathrm{x} 10^{\wedge} 3 / \mu \mathrm{L}$ & 117.02 & 286.61 & $<0.001$ & Yes \\
\hline NLR & - & 18.62 & 6.56 & $<0.001$ & Yes \\
\hline LCR & - & 0.14 & 1.31 & 0.002 & Yes \\
\hline
\end{tabular}

\section{Discussion}

COVID-19 severity can be classified into three groupsnamely "early infection", "pulmonary phase" and "hyperinflammation phase", each one has its own biochemical and hematological alterations [23]. Patients in early infection stage present with fever, dry cough and other non- specific symptoms due to presence of innate immunity. Lymphocytopenia is remarkable at this stage [24]. In the pulmonary phage the hallmark of infection is lymphopenia and elevated level of CRP and most patients require hospitalization. In hyperinflammation phase, most of the patients require ICU admission due to development of ARDS and MOF because of significantly increase of several inflammatory biomarkers [25].
In our study, we observed lymphocytopenia in expired patients. Hypothesis from different studies suggest that it is due to direct attack of T-cells by virus and or it may be proinflammatory cytokines induced lymphocyte deficiency mainly, IL-6 and TNF-alpha [26,27,28,29]. Studies showed that neutrophil to lymphocyte ratio (NLR) increases the risk of death of hospitalized COVID-19 patients which coincides with our study [30]. Among the COVID-19 patients who died in the ICU, those over 60 had more WBCs. Systemic inflammatory response syndrome (SIRS) was more likely to grow in COVID-19 patients with a high leukocyte count [19]. Some of the patients who recovered from COVID-19 had slightly higher WBCs. 
Thrombocytopenia is a significant observation of this study which corresponds other studies. Many studies suggest that it may occur due to direct invasion of virus to bone marrow stomal cell or destruction of platelet in injured lung tissue leads to activation, aggregation and retention of platelets in lungs. Decreased platelet production and increased consumption ultimately leads to thrombocytopenia [31,32].

In this study, D-dimer test showed statistically significant difference between patients who died in the ICU which correlates with several studies. Increased D-dimer value in severe COVID-19 patients reflect the coagulation alteration which is associated with poor outcome as there is increased risk of ARDS, DIC, ICU admission and mortality [33, 34, 35]. Ferritin is another statistically highly significant biomarker found in our study. Patients who died in the ICU, ferritin levels observed more than 15 times higher compared to cured patients. Scientists discovered that elevated level of ferritin as the disease progresses, indicating a higher risk of death which matches with our study [36].

In our study, COVID-19 patients who died in the ICU had about 10 times higher CRP levels than the cured patients which coincides with other different studies [37,38,39]. There is a direct relationship between increased CRP level and disease severity at early stage of diseases. CRP has a good diagnostic accuracy and early predicting severe COVID-19 at a cutoff value of $2.042 \mathrm{mg} / \mathrm{dl}$ [40].

It is a limitation of our study that we don't have the preliminary data of electrolyte of patients, rather the corrected value is available here. In maximum cases of our study, we found the values are within the ranges. Therefore, we did not find the true correlation of electrolyte imbalance though several studies showed Hyponatremia, Hypocalcemia, and Hypokalemia is very common in severe cases of COVID-19 infection [41].They mentioned the GIT impairments diarrhoea and or viral interaction to ACE2 receptor leads to elevated level of angiotensin II resulting in increased potassium excretion turns to Hypokalemia.

\section{Conclusions}

Laboratory medicine plays a vital role to identify critically ill patient even before severe clinical manifestations and thus improve the recovery which ultimately reduce mortality rate. Many hematological and biochemical parameters have been associated with poor outcome and represent for predicting severe COVID-19 in order to guide for proper clinical care. Among the parameters, Leukocytosis, Lymphocytopenia, Thrombocytopenia, Electrolyte Imbalance, CRP, D-Dimer, Ferritin, IL-6 are the most common predicting parameters of severe COVID-19. In addition to traditional biochemical and hematological markers it would be interesting to assess the role of new promising biomarkers, such as NLR and LCR for early identification of patients at increased risk of complications. Elevated level of NLR and decreased level of LCR are directly correlated with disease severity and mortality, which is consistent with this study. It is a single centered study. So, there is a lack of diversity of population. A large-scale multi-centric study is recommended for further evaluation.

\section{Disclosure statement}

The authors declare no conflicts of interest with this article's content.

\section{Funding}

This work is not supported by any sponsors. No funding required in this study.

\section{Author contributions}

All authors have accepted responsibility for the entire content of this manuscript and approved its submission.

\section{References}

[1]. Covid map: coronavirus cases, deaths, vaccinations by country. https://www.bbc.com/news/world-51235105

[2]. Countries where COVID-19 has spread- worldometer. https://www.worldometers.info/ coronavirus/countries-wherecoronavirus-has-spread/

[3]. Ciaccio M, Agnello L (2020). Biochemical biomarkers alterations in Coronavirus Disease 2019 (COVID-19). Diagnosis (Berl). 7(4):365-72.

[4]. Driggin E, Madhavan MV, Bikdeli B, Chuich T, Laracy J, Biondi-Zoccai G, et al. (2020). Cardiovascular considerations for patients, health care workers, and health systems during the COVID-19 pandemic. J Am Coll Cardiol. 75(18):2352-71. [5]. Xiao F, Tang M, Zheng X, Liu Y, Li X, Shan H (2020). Evidence for gastrointestinal infection of SARS-CoV-2. Gastroenterology. 158(6):1831-1833.e3.

[6]. Medetalibeyoglu A, Catma Y, Senkal N, Ormeci A, Cavus B, Kose M, et al. (2020). The effect of liver test abnormalities on the prognosis of COVID-19. Ann Hepatol. 19(6):614-21.

[7]. Adapa S, Chenna A, Balla M, Merugu GP, Koduri NM, Daggubati SR, et al. (2020). COVID-19 pandemic causing acute kidney injury and impact on patients with chronic kidney disease and renal transplantation. J Clin Med Res. 12(6):352-61.

[8]. Ellul MA, Benjamin L, Singh B, Lant S, Michael BD, Easton A, et al. (2020). Neurological associations of COVID19. Lancet Neurol. 19(9):767-83.

[9]. Broxmeyer HE, Parker GC (2020). Impact of COVID-19 and future emerging viruses on hematopoietic cell transplantation and other cellular therapies. Stem Cells Dev. 29(10):625-6.

[10]. Tay MZ, Poh CM, Rénia L, MacAry PA, Ng LFP. The trinity of COVID-19: immunity, inflammation and intervention. Nat Rev Immunol. 20(6):363-74.

[11]. Lippi G, Plebani M (2020). The critical role of laboratory medicine during coronavirus disease 2019 (COVID-19) and other viral outbreaks. Clin Chem Lab Med. 58(7):1063-9

[12]. Sanyaolu A, Okorie C, Marinkovic A, Patidar R, Younis K, Desai P, Hosein Z, Padda I, Mangat J, Altaf M (2020). Comorbidity and its impact on patients with COVID-19. SN Compr Clin Med. Jun 25: 1-8.

[13]. Lippi G, Plebani M (2020). Laboratory abnormalities in patients with COVID-19 infection. Clin Chem Lab Med. 58:1131-4.

[14]. Argyropoulos KV, Serrano A, Hu J, Black M, Feng X, Shen G, Call N et al. (2020). Association of Initial Viral Load in Severe Acute Respiratory Syndrome Coronavirus 2 (SARS COV2) Patients with Outcome and Symptoms. The American Journal of Pathology, Vol. 190, No. 9, September 2020. 
[15]. Zhang J-J, Cao Y-Y, Dong X, Wang B-C, Liao M-Y, Lin J, et al. (2020). Distinct characteristics of COVID-19 patients with initial rRT-PCR-positive and rRT-PCR-negative results for SARS-CoV-2. Allergy. 75(7):1809-12

[16]. Henry BM, de Oliveira MHS, Benoit S, Plebani M, Lippi G. (2020). Hematologic, biochemical and immune biomarker abnormalities associated with severe illness and mortality in coronavirus disease 2019 (COVID-19): a meta-analysis. Clin Chem Lab Med. 58(7):1021-8

[17]. Shang Y, Pan C, Yang X, Zhong M, Shang X, Wu Z, Yu Z, Zhang W, Zhong Q, Zheng X, Sang L, Jiang L, Zhang J, Xiong W, Liu J, and Chen D (2020). Management of critically ill patients with COVID-19 in ICU: statement from front-line intensive care experts in Wuhan, China. Ann Intensive Care. 10: 73.

[18] Fa'1co-Filho KS, Passarelli VC et al. (2020). Is Higher Viral Load in SARS-CoV-2 Associated with Death? Am. J. Trop. Med. Hyg., 103(5)pp

[19]. Lee JS, Kim NY, Na SH, et al. (2018). Reference value of neutrophil-lymphocyte ratio, lymphocyte-monocyte ratio, platelet-lymphocyte ratio, and mean platelet volume in healthy adults in South Korea. Medicine (Baltimore). 97:26.

[20]. Sato H, Tsubosa Y, Kawano T (2012). Correlation between the pretherapeutic neutrophil to lymphocyte ratio and the pathologic response to neoadjuvant chemotherapy in patients with advanced esophageal cancer. World J Surg. 36(3):617-622. PMID 22223293

[21]. Chen Z, Fan H, Cai J, Li Y, Wu B, Hou Y, Xu S, Zhou F, Liu Y, Xuan W, Hu H (2020). High- resolution computed tomography manifestations of COVID-19 infections in patients of different ages. European journal of radiology. May 1;126: 108972.

[22]. Asghar MS, Khan NA, Kazmi SJH, Ahmed A, Hassan M, Jawed R, Akram M, Rasheed U, Memon GM, Ahmed MU, Tahniyat U \& Tirmizi SB (2020). Hematological parameters predicting severity and mortality in COVID-19 patients of Pakistan: a retrospective comparative analysis

Journal Of Community Hospital Internal Medicine Perspectives. VOL. 10, NO. 6, 514-520; https://doi.org/10.1080/20009666.2020.1816276

[23]. Siddiqi HK, Mehra MR (2020). COVID-19 illness in native and immunosuppressed states: a clinical-therapeutic staging proposal. J Heart Lung Transplant. https://doi.org/10.1016/j.healun. 2020.03.012.

[24]. Ciaccio $M$ and Agnello L (2020). Biochemical biomarkers alterations in Coronavirus Disease 2019 (COVID19). Diagnosis. 7(4): 365-372. https://doi.org/10.1515/dx2020-0057

[25]. Xu Z, Shi L, Wang Y, Zhang J, Huang L, Zhang C, et al.(2020). Pathological findings of COVID-19 associated with acute respiratory distress syndrome. Lancet Respir Med. $8: 420-2$.

[26]. Guan WJ, Ni ZY, Hu Y, Liang WH, Ou CQ, He JX, et al. (2020). Clinical characteristics of coronavirus disease 2019 in China. N Engl J Med. https://doi.org/10.1056/NEJMoa 2002032.

[27]. Chen N, Zhou M, Dong X, Qu J, Gong F, Han Y, et al. (2020). Epidemiological and clinical characteristics of 99 cases of 2019 novel coronavirus pneumonia in Wuhan, China: a descriptive study. Lancet. 395:507-13.
[28]. Huang C, Wang Y, Li X, Ren L, Zhao J, Hu Y. et al. (2020). Clinical features of patients infected with 2019 novel coronavirus in Wuhan, China. Lancet. 395:497-506.

[29]. Liao YC, Liang WG, Chen FW, Hsu JH, Yang JJ, Chang MS (2002). IL-19 induces production of IL-6 and TNF-alpha and results in cell apoptosis through TNF-alpha. J Immunol. 169:4288-97.

[30]. Liu Y, Du X, Chen J, Jin Y, Peng L, Wang HHX, et al. (2020). Neutrophil-tolymphocyte ratio as an independent risk factor for mortality in hospitalized patients with COVID-19. J Infect. https://doi.org/10.1016/j.jinf.2020.04.002.

[31]. Pilaczyńska-Cemel $\mathrm{M}$, Gołda R, Dąbrowska A, Przybylski G (2019). Analysis of the level of selected parameters of inflammation, circulating immune complexes, and related indicators

(neutrophil/lymphocyte, platelet/lymphocyte, CRP/CIC) in patients with obstructive diseases. Cent Eur J Immunol. 44:292-8.

[32]. Shinya K, Gao Y, Cilloniz C, Suzuki Y, Fujie M, Deng G et al. (2012). Integrated clinical, pathologic, virologic, and transcriptomic analysis of $\mathrm{H} 5 \mathrm{~N} 1$ influenza virus-induced viral pneumonia in the rhesus macaque. J Virol. 86:6055-66.

[33]. Zhou F, Yu T, Du R, Fan G, Liu Y, Liu Z, et al. (2020). Clinical course and risk factors for mortality of adult inpatients with COVID-19 in Wuhan, China: a retrospective cohort study. Lancet. 395: 1054-62.

[34]. Tang N, Bai H, Chen X, Gong J, Li D, Sun Z (2020). Anticoagulant treatment is associated with decreased mortality in severe coronavirus disease 2019 patients with coagulopathy. J Thromb Haemost. https://doi.org/10.1111/jth.14817

[35]. Wu C, Chen X, Cai Y, Xia J, Zhou X, Xu S (2020). Risk factors associated with acute respiratory distress syndrome and death in patients with coronavirus disease 2019 pneumonia in Wuhan, China. JAMA Intern Med. https://doi.org/10.1001/jamainternmed.2020. 0994

[36]. Akizawa T, Gejyo F, Nishi S, Iino Y, Watanabe Y, Suzuki M, Saito A, Akiba T, Hirakata H, Fukuhara S, Morita S (2011). Positive outcomes of high hemoglobin target in patients with chronic kidney disease not on dialysis: a randomized controlled study. Therapeutic Apheresis and Dialysis. Oct;15(5):431-40.

[37]. Yang W, Cao Q, Qin L, Wang X, Cheng Z, Pan A, et al. (2020). Clinical characteristics and imaging manifestations of the 2019 novel coronavirus disease (COVID-19): a multicenter study in Wenzhou city, Zhejiang, China. J Infect. 80: $388-93$.

[38]. Wang D, Hu B, Hu C, Zhu F, Liu X, Zhang J, et al. (2020). Clinical characteristics of 138 hospitalized patients with 2019 novel coronavirus-infected pneumonia in Wuhan, China. J Am Med Assoc. 323: 1061-69. https://doi.org/10.1001/jama.2020. 1585

[39]. Matsumoto H, Kasai T, Sato A, Ishiwata S, Yatsu S, Shitara J, et al. (2019). Association between C-reactive protein levels at hospital admission and long-term mortality in patients with acute decompensated heart failure. Heart Ves.34: 1961-8.

[40]. Tan C, Huang Y, Shi F, Tan K,MaQ, Chen Y, et al. (2020). C-reactive protein correlates with CT findings and predicts severe COVID-19 early. 370 Ciaccio and Agnello: Biomarkers in COVID-19 J Med Virol. 
https://doi.org/10.1002/jmv.25871

[41]. Lippi G, South AM, Henry BM (2020). Annals express: electrolyte imbalances in patients with severe coronavirus disease 2019 (COVID-19). Ann Clin Biochem. https://doi.org/10.1177/ 0004563220922255 